\title{
A produção científica sobre Qualidade de Vida no Trabalho no período de 1995 a 2020 nas bases: CAPES, EBSCO HOST E SPELL
}

\section{The scientific production on Quality of Life at Work from 1995 to 2020 in the bases: CAPES, EBSCO HOST and}

\author{
Muira Helena Batista ${ }^{1}$ \\ Mário Teixeita Reis Neto ${ }^{2}$ \\ Danile Jardim Pardini ${ }^{3}$ \\ Iris Barbosa Goulart ${ }^{4}$
}

\begin{abstract}
Resumo
O presente trabalho tem o objetivo de analisar a produção científica sobre Qualidade de Vida no Trabalho, no período de 1995 a 2020. Foram pesquisadas as seguintes bases de dados: Periódicos CAPES, EBSCO HOST e SPELL. Trata-se de estudo bibliométrico com objetivo de verificar a produção científica nacional e seus avanços. Os resultados apontam uma insatisfação nas dimensões de remuneração e premiação, autonomia e participação nas decisões, tanto em empresas públicas quanto privadas. Para a administração pública, é necessário observar as restrições da Lei de Responsabilidade Fiscal. Já no poder Judiciário e em empresas privadas, há insatisfação com a má organização/distribuição do trabalho, fator que pode gerar adoecimento dos indivíduos. As minorias, mulheres e pessoas com deficiências, estão satisfeitas com a QVT nos seus locais de trabalho. Conclui-se que na avaliação, QVT possui índices satisfatórios, em sua maioria, e que as dimensões com índices insatisfatórios devem ser melhoradas a fim de evitar adoecimento, desses trabalhadores.
\end{abstract}

Palavras-chave: Qualidade de Vida no Trabalho. Administração Pública. Organizações, Estresse. Modelos de QVT.

\begin{abstract}
This work aims to analyze the scientific production on Quality of Life at Work, from 1995 to 2020, in the following databases: CAPES Periodicals, EBSCO HOST and SPELL. It is a bibliometric study with the objective of verifying the national scientific production and its advances. The results point to dissatisfaction in the dimensions of remuneration and reward, autonomy and participation in decisions, both in public and private companies. For the public administration, the restrictions of the Fiscal Responsibility Law should be observed. In the Judiciary and in private companies, there is dissatisfaction with the organization of work, a factor that can generate illness among individuals. Minorities, women and people with disabilities, are satisfied with the QLW of their workplaces. It is concluded that QLW has satisfactory rates, in its majority, and that the dimensions with unsatisfactory rates must be improved in order to avoid illness.
\end{abstract}

Keywords: Quality of Life at Work. Public Administration. Organizations, Stress. QVT Models.

\footnotetext{
${ }^{1}$ Mestre em Administração pelo Centro Universitário UNA. FUMEC. E-mail: muirahelena@yahoo.com.br

${ }^{2}$ Doutor em Administração pela Universidade Federal de Minas Gerais (2004). Professor do Programa de Doutorado e Mestrado em Administração da Universidade FUMEC. E-mail: reisnetomario@gmail.com

${ }^{3}$ Doutor em Administração pelo CEPEAD-UFMG-Birmingham University. Professor do Programa de Doutorado e

Mestrado em Administração da FACE-FUMEC e do Programa de Doutorado e Mestrado em Sistemas de Informação e Gestão do Conhecimento da Universidade FUMEC. E-mail: pardini@fumec.br

${ }^{4}$ Doutora em Psicologia pela Pontifícia Universidade Católica de São Paulo (1985). Coordenadora do Núcleo de Pesquisa e Pós-graduação do LATACI Research Institute. E-mail: irisbgoulart@gmail.com
}

Artigo recebido em: 09 de agosto de 2020. Artigo aceito em 14 de Fevereiro de 2021. 


\section{Introdução}

Devido à influência da globalização, as empresas estão inseridas em um mercado altamente competitivo, no qual os ganhos e as perdas de produtividade são considerados cruciais para o seu sucesso. Nesse cenário competitivo, em 1980, nos Estados Unidos, o tema Qualidade de Vida no Trabalho (doravante QVT) retorna à cena (ROSALINO; BARDAGI, 2008). O estudo de qualidade de vida no trabalho surgiu devido à necessidade de melhorar a qualidade e a produtividade das empresas. A QVT tem duas vertentes de atuação para que a organização atinja os seus objetivos, os quais são o bemestar dos profissionais e a eficácia organizacional (SANTOS, et al., 2019).

A QVT tem o ser humano como o centro motor, e procura oferecer ao trabalhador boas condições laborais para o desenvolvimento de suas tarefas, com satisfação e bemestar. O indivíduo deve estar pleno para exercer suas atividades laborais e a organização deve lhe oferecer condições adequadas para tal. As ideias centrais da QVT convergem para um ponto comum: reduzir efeitos indesejáveis dos pontos de tensão entre indivíduo e organização (SOUZA; MEDEIROS, 2007).

O indivíduo tem expectativas para serem alcançadas, e uma delas é viver satisfatoriamente bem, evidenciando que suas conquistas só valem a pena quando acompanhadas por uma vida tranquila, que compreende o gozo pleno dos seguintes aspectos: emocional, saúde física, relacionamentos familiares e sociais, especialmente no ambiente de trabalho, que lhe traga realização e bem-estar (LUZ; SOUZA; SILVA, 2011).

O indivíduo deve gozar de saúde para prestar um bom serviço, salientando que o colaborador sem saúde não rende o esperado pela empresa, ou seja, a saúde é um aspecto fundamental para a QVT. Logo, as organizações devem buscar implementar mudanças de hábitos em seus colaboradores (LUZ; SOUZA; SILVA, 2011). O estresse no local de trabalho e a falta de um estilo de vida saudável têm levado ao adoecimento dos indivíduos, consequentemente, a faltas no trabalho ou ao seu desligamento (BOTH et al., 2010; SILVA, et al., 2018).

Esta pesquisa se justifica devido a relevância da QVT para o mundo do trabalho, mesmo com todos os avanços que ocorrem nos últimos anos, as pesquisas cientificas apontam que em períodos de crises, tais como os que surgiram no século passado, 
durante a crise do petróleo que ocorreu nos anos de 1970 o tema ficou adormecido nas organizações, normalmente nestes períodos os investimentos em QVT são reduzidos ou extintos (ROSALINO; BARDAGI, 2008). A Pandemia de Covid-19 trouxe para as relações de trabalho alterações, que torna mister revisitar o tema na busca de um novo olhar para a QVT. As medidas para conter o avanço da Pandemia de Covid-19, trouxeram o isolamento social e as alterações das relações de trabalho devido a implantação do home office, e com a redução do quadro funcional presencial, onde o trabalho não pode ser executado remotamente. Com o afastamento do grupo de risco e com uma quantidade menor de trabalhadores para executarem as mesmas tarefas houve uma degradação nessas relações de trabalho e saúde.

Este estudo é composto desta breve introdução, seguida da conceituação do constructo Qualidade de Vida no Trabalho, a metodologia adotada nesta pesquisa, os resultados encontrados, discussões dos resultados e as considerações finais.

\section{A Evolução do conceito de Qualidade de Vida no Trabalho}

O termo Qualidade de Vida no Trabalho, de acordo com Rosalino e Bardagi (2008), teve início nos anos 1950, na Inglaterra, com os trabalhos de Eric Trist e seus colaboradores, que estudaram a relação entre o indivíduo, trabalho e organização. Nesse contexto da abordagem sociotécnica da organização emergiu a temática satisfação do trabalhador na organização e com o trabalho. Nos estudos observaram que a satisfação era um dos aspectos fundamentais para o indivíduo em relação ao trabalho (GOULART; SAMPAIO, 2004). Na década de 1960, as pesquisas que focavam o bem-estar do trabalhador, tanto pelo viés da saúde física quanto psicológica (LÍRIO; SEVERO; GUIMARÃES, 2018; ROSALINO; BARDAGI, 2008).

Houve uma queda no interesse de estudos que abordam a QVT a partir de 1974, devido à crise do petróleo e o processo inflacionário que tem reflexo em todos os países do mundo capitalista. Neste período as organizações passaram a não observar seus funcionários, os quais ficaram em segundo plano. Em 1979, com o fim dos conflitos enérgicos e a inflação controlada, a QVT ressurgiu, como consequência da perda de produtividade da indústria americana para a concorrência japonesa (ROSALINO; BARDAGI, 2008).

O grande boom de QVT ocorre nos anos de 1980 nos Estados Unidos com o ressurgimento do tema, com os estudos de Huse e Cumings (1985) que citaram também 
pesquisas de Davis e outros que em 1957 visavam modificar a linhas de montagem nos Estados Unidos, para tornar o trabalho mais agradável e saudável (GOULART; SAMPAIO, 2004).

A Organização Mundial da Saúde (OMS) adota o tema Qualidade de Vida por meio de abordagens gerais ou holísticas baseadas em cinco dimensões: Saúde física, Saúde psicológica, nível de independência, relações sociais e meio ambiente (OMS, 1998). Nessa abordagem a qualidade de vida tem como princípio refletir a percepção dos indivíduos de que suas necessidades estão sendo satisfeitas, ou as oportunidades que lhes estão sendo negadas de alcançar a felicidade e a autorrealização, independente do seu estado de saúde físico ou das condições sociais e econômicas (PEREIRA; TEIXEIRA; SANTOS, 2012).

No Brasil, a QVT ganhou força a partir da década de 1980, quando as pesquisas foram fortemente influenciadas pelos estudos estrangeiros (ROSALINO; BARDAGI, 2008). Nesse período, a QVT se tornou um conceito global, e com a participação do trabalhador na empresa, o trabalho se tornou mais humanizado (ARELLANO; LIMONGI-FRANÇA, 2013).

O tema QVT é considerado um conceito multidimensional, que abrange os sentimentos de um empregado sobre várias questões do trabalho, como o conteúdo do trabalho, condições de trabalho, compensação justa e adequada, oportunidades de desenvolvimento de carreira, existência de descrição de tarefas, participação na tomada de decisões, saúde e segurança ocupacional, estresse no trabalho, organização e relações interpessoais e equilíbrio da vida no trabalho. A QVT, por ser um tema multidimensional, tem uma base teórica desenvolvida em várias áreas do conhecimento, e pesquisas desenvolvidas nas ciências humanas, sociais e sociais aplicadas (PANUCCI-FILHO; HEIN; KROENKE, 2017). Em todos os estudos se busca conhecer e compreender as nuances que influenciam a percepção do indivíduo quanto à QVT da organização em que se trabalha.

O trabalho de Hackman e Oldham (1974) tem como pressupostos que a QVT é atingida quando três estados psicológicos são percebidos pelo indivíduo como presentes, que são: significância percebida do trabalho, responsabilidade percebida pelos resultados do trabalho e o conhecimento que esse trabalho gera. Estes estados devem estar presentes para que o indivíduo alcance resultados positivos.

O conceito de QVT de Walton (1973) tem como base a humanização e a 
responsabilidade social como critérios fundamentados na dimensão organizacional, considerando o poder da empresa. Para atingir o seu objetivo de mensurar a QVT, ele formulou sua metodologia de avaliação em oito categorias: i) compensação justa e adequada; ii) condições de trabalho seguras e saudáveis; iii) oportunidades imediatas para desenvolver e usar a capacidade do ser humano; iv) oportunidades futuras para crescimento profissional; v) integração social na organização; vi) constitucionalismo; vii) trabalho e o espaço total na vida do trabalhador; e, viii) relevância social do trabalho.

Os estudos de QVT no Brasil contam com a colaboração de Fernandes (1996) e Limongi-França (2006). O conceito de QVT, de acordo com Fernandes (FERNANDES, 1996), evoluiu de acordo com a humanização do trabalho, a responsabilidade social da empresa e o atendimento das aspirações e necessidades dos indivíduos. O sucesso empresarial passou a ter como foco para seu atingimento a premissa de atender à satisfação do bem-estar no trabalho do seu quadro funcional.

No conceito de QVT, de Limongi-França (2006), a organização desempenha papel-chave em diferenciar e identificar as demandas de QVT. O modelo tem como pressuposto que todas as dimensões respondem simultaneamente às condições de vida $\mathrm{e}$ que o sucesso depende de um equilíbrio entre elas. As demandas de QVT devem considerar o domínio biológico, psicológico, social e organizacional. No Quadro 1 são apresentados os principais modelos internacionais e nacionais e as premissas que os norteiam.

Quadro 1 - Modelos teóricos em QVT

\begin{tabular}{|l|l|}
\hline Modelo Teórico & Dimensões Consideradas \\
\hline Walton (1973) & $\begin{array}{l}\text { 1) Compensação justa e adequada; 2) Condições de trabalho } \\
\text { seguras e saudáveis; 3) Oportunidades imediatas para } \\
\text { desenvolver e usar as capacidades humanas; 4) Oportunidades } \\
\text { futuras para o crescimento contínuo; 5) Integração social na } \\
\text { organização; 6) Constitucionalismo na organização; 7) } \\
\text { Trabalho e espaço total na vida; 8) Relevância social do } \\
\text { trabalho. }\end{array}$ \\
\hline $\begin{array}{l}\text { Hackman e Oldhan } \\
(1974)\end{array}$ & $\begin{array}{l}\text { 1.) Variedade de Habilidade; 2) Identidade da Tarefa; 3) } \\
\text { Significado da Tarefa; 4) Inter-relacionamento; 5) Autonomia; } \\
\text { 6) Feedback }\end{array}$ \\
\hline Westley (1979) & \begin{tabular}{l} 
1) Econômica; 2) Política; 3) Psicológica; 4) Sociológica \\
\hline
\end{tabular} \\
\hline
\end{tabular}




\begin{tabular}{|l|l|}
\hline $\begin{array}{l}\text { Werther e Davis } \\
(1983)\end{array}$ & 1) Organizacional; 2) Ambiental; comportamental \\
\hline Fernandes (1996) & $\begin{array}{l}\text { 1) Condições de Trabalho; 2) Saúde; 3) Moral; 4) } \\
\text { Compensação; 5) Participação; 6) Comunicação; 7) Imagem } \\
\text { Empresa; 8) Relação Chefe/subordinado; 9) Organização do } \\
\text { Trabalho; }\end{array}$ \\
\hline $\begin{array}{l}\text { Limongi-França } \\
\text { (2006) }\end{array}$ & $\begin{array}{l}\text { 1) BEO - Bem-estar Organizacional; 2) Produtividade; 3) } \\
\text { Legitimidade; 4) Perfil dos líderes; 5) Práticas e Valores; 6) } \\
\text { Nova Competência }\end{array}$ \\
\hline
\end{tabular}

Fonte: Elaborado pelos autores a partir dos trabalhos que compõem o estudo

No quadro 1 é possível verificar a evolução dos estudos de QVT no Brasil e no mundo, as contribuições que trouxeram os estudos de Fernandes (1996) e LimongiFrança $(1998,2006)$ com a investigação das influências de QVT nas rotinas das organizações e neste cenário despontam novos pesquisadores.

Dentro deste vasto arcabouço teórico, encontramos vários estudos de QVT na literatura que integra este estudo para bem-estar no trabalho. No quadro 2, apresentamos os artigos de seminários na área de QVT no Brasil, dos quais são artigos com 25 anos de publicação que abordam os primeiros estudos na área, e que formam base teórica para os estudos atuais.

Quadro 2 - Alguns estudo nacionais relacionados com QVT.

\begin{tabular}{|l|l|}
\hline Autor & Breve descrição do Estudo \\
\hline Flbuquerque e Limongi- & $\begin{array}{l}\text { O objetivo da pesquisa é investigar a influência da } \\
\text { Qualidade Total por meio da ISO 9000, os aspectos do } \\
\text { stress e seus reflexos na qualidade de vida no trabalho. } \\
\text { Os resultados encontrados dizem que as empresas neste } \\
\text { período passam a compreender e investigar o estresse e } \\
\text { as doenças associadas às pressões organizacionais. Neste } \\
\text { momento, há a expansão do conceito de qualidade total } \\
\text { em um ambiente competitivo. Toda essa movimentação } \\
\text { gera a necessidade de um novo posicionamento por parte } \\
\text { dos gestores de pessoas nas organizações e as ações de } \\
\text { QVT passam a integrar as estratégias de recursos } \\
\text { humanos. }\end{array}$ \\
\hline $\begin{array}{l}\text { Monaco e Guimarães } \\
(2000)\end{array}$ & $\begin{array}{l}\text { O objetivo é avaliar as transformações dos aspectos } \\
\text { relacionados à qualidade de vida no trabalho a partir da } \\
\text { introdução do programa de qualidade total numa } \\
\text { empresa pública prestadora de serviços. É um estudo } \\
\text { qualitativo, com análise de conteúdo com os critérios de }\end{array}$ \\
\hline
\end{tabular}




\begin{tabular}{|c|c|}
\hline & $\begin{array}{l}\text { Walton para a categorização. A pesquisa tem por } \\
\text { objetivo verificar a qualidade de vida no trabalho como } \\
\text { uma expansão natural da qualidade total, de forma que } \\
\text { os programas de qualidade total melhoram os resultados } \\
\text { das empresas, mas também a satisfação, o bem-estar e a } \\
\text { condição de vida das pessoas. }\end{array}$ \\
\hline Tolfo e Piccinini (2001) & $\begin{array}{l}\text { A pesquisa foi conduzida à luz dos critérios de Walton } \\
\text { (1973) com as melhores empresas de trabalhar em } \\
\text { 1997,98, 99 e } 2000 \text { a partir de inferências do } \\
\text { questionário de Walton. Os resultados encontrados na } \\
\text { pesquisa demonstram que as organizações cujas práticas } \\
\text { de QVT foram avaliadas de forma mais positiva pelos } \\
\text { seus empregados nos anos de } 1997 \text { e } 1999 \text { enfatizam, em } \\
\text { primeiro lugar, o orgulho do trabalho e da empresa. No } \\
\text { ano 2000, o principal aspecto valorizado foi a } \\
\text { oportunidade de carreira e treinamento. No conjunto, } \\
\text { observou-se uma redução do número de empresas e de } \\
\text { itens em relação aos quais elas receberam a avaliação } \\
\text { máxima por parte dos empregados. }\end{array}$ \\
\hline Rocha e Felli (2004) & $\begin{array}{l}\text { É um estudo qualitativo com análise de conteúdo das } \\
\text { entrevistas, no qual as autoras constataram que os } \\
\text { docentes de enfermagem estão insatisfeitos com as } \\
\text { dimensões de QVT devido aos diversos problemas de } \\
\text { saúde que permitem evidenciar os fatores desgastantes } \\
\text { que se sobrepõem aos fatores potencializadores. Mesmo } \\
\text { o investimento na capacitação do corpo docente ser } \\
\text { citado, não minimiza o impacto referente ao regime de } \\
\text { trabalho, baseado no sistema hora/aula, demostrando a } \\
\text { fragilidade institucional, considerando a sua repercussão } \\
\text { sobre a QVT dos docentes de enfermagem. Os } \\
\text { resultados evidenciam a importância de se implementar } \\
\text { uma política institucional que explicite valores e } \\
\text { interesses básicos e que reflita o investimento em } \\
\text { melhores condições de trabalho. }\end{array}$ \\
\hline $\begin{array}{l}\text { Oliveira e Limongi-França } \\
(2005)\end{array}$ & $\begin{array}{l}\text { O artigo investiga a percepção dos administradores } \\
\text { sobre a possibilidade de se avaliar os resultados da } \\
\text { Gestão de QVT. Para atingir o objetivo, realizou-se uma } \\
\text { pesquisa quantitativa com os fatores críticos de gestão. } \\
\text { Os resultados encontrados ratificam a necessidade de } \\
\text { difusão de práticas para avaliação de resultados, e que as } \\
\text { avaliações devem utilizar de indicadores com } \\
\text { transparência. }\end{array}$ \\
\hline $\begin{array}{l}\text { Ferreira, Alves e } \\
\text { (2009) }\end{array}$ & $\begin{array}{l}\text { O estudo é diagnóstico qualitativo, no qual se } \\
\text { constataram os conflitos da implantação de um } \\
\text { programa efetivo de QVT na administração pública. A } \\
\text { pesquisa foi conduzida em } 10 \text { órgãos da administração } \\
\text { pública. Os resultados encontrados evidenciam que as }\end{array}$ \\
\hline
\end{tabular}

Revista Eletrônica Gestão e Serviços v.12, n. 1, pp. 3382 - 3411, Janeiro/Junho 2021. ISSN Online: 2177-7284 e-mail: $\underline{\text { regs@metodista.br }}$ 


\begin{tabular}{|l|l|}
\hline & $\begin{array}{l}\text { práticas de QVT se caracterizam por nítido descompasso } \\
\text { entre problemas existentes e atividades realizadas, com } \\
\text { uma abordagem de QVT de viés assistencialista, que } \\
\text { tem no trabalhador a variável de ajuste. }\end{array}$ \\
\hline
\end{tabular}

Fonte: Elaborado pelos autores a partir dos trabalhos que compõe o estudo

Nesse quadro é possível verificar que os estudos em QVT vêm ganhando força ao longo do tempo, e que as investigações são tanto para compreender as pressões que os trabalhadores de empresas privadas passam com a implantação de programas de qualidade total, quanto os servidores públicos percebem as melhorias geradas pelos programas de QVT implantados em suas unidades.

\section{METOLOGIA}

Esta pesquisa, pela abordagem, se caracteriza como quantitativa, quanto aos meios, como bibliográfica. A coleta de dados se dará nas bases de dados da CAPES, Ebsco Host e SPELL, para o período de 1995 a 2020. Por ser um estudo bibliográfíco classifica-se como descritivo por se desenvolver com material já elaborado, os artigos científicos.

Nos procedimentos de coleta de dados, os seguintes aspectos são observados:

a) Seleção das bases de dados CAPES, Ebsco Host por serem assinadas pela instituição dos pesquisadores e SPELL pelo livre acesso;

b) Determinação do período a ser coberto pela investigação - 1995 a 2020;

c) Determinação das palavras-chave a serem usadas na busca bibliográfica qualidade de vida no trabalho (QVT) no título da pesquisa;

d) Realização da busca nas bases de dados com e nas palavras-chave;

e) Refinamento dos artigos encontrados a partir da leitura do título e do abstract, pois alguns dos artigos não se encaixavam no escopo deste estudo;

f) Exclusão de artigos repetidos da amostra.

Para compor este estudo, a amostra inicial obtida nas bases citadas foi de 216 artigos, após o refinamento e exclusão dos repetidos ficou com 135 artigos para serem analisados. Os artigos serão analisados quanto aos construtos que os norteiam, os resultados alcançados e as contribuições para o avanço das pesquisas nessa área do conhecimento.

Revista Eletrônica Gestão e Serviços v.12, n. 1, pp. 3382 - 3411, Janeiro/Junho 2021. ISSN Online: 2177-7284 e-mail: regs@metodista.br 


\section{RESULTADOS}

O tema QVT se desenvolveu no mundo a partir dos anos de 1950. Devido à crise do petróleo, nos anos 1970, o tema foi deixado de lado. A QVT retorna devido à concorrência japonesa a partir de 1979, nos Estados Unidos e no Brasil a partir de 1980 (ROSALINO; BARDAGI, 2008).

A análise bibliométrica a respeito do tema QVT demostra que não se trata de modismo, mas que o tema vem se consolidando nos centros de pesquisas do país, conforme o gráfico 1 .

Gráfico 1: Produção de Artigos

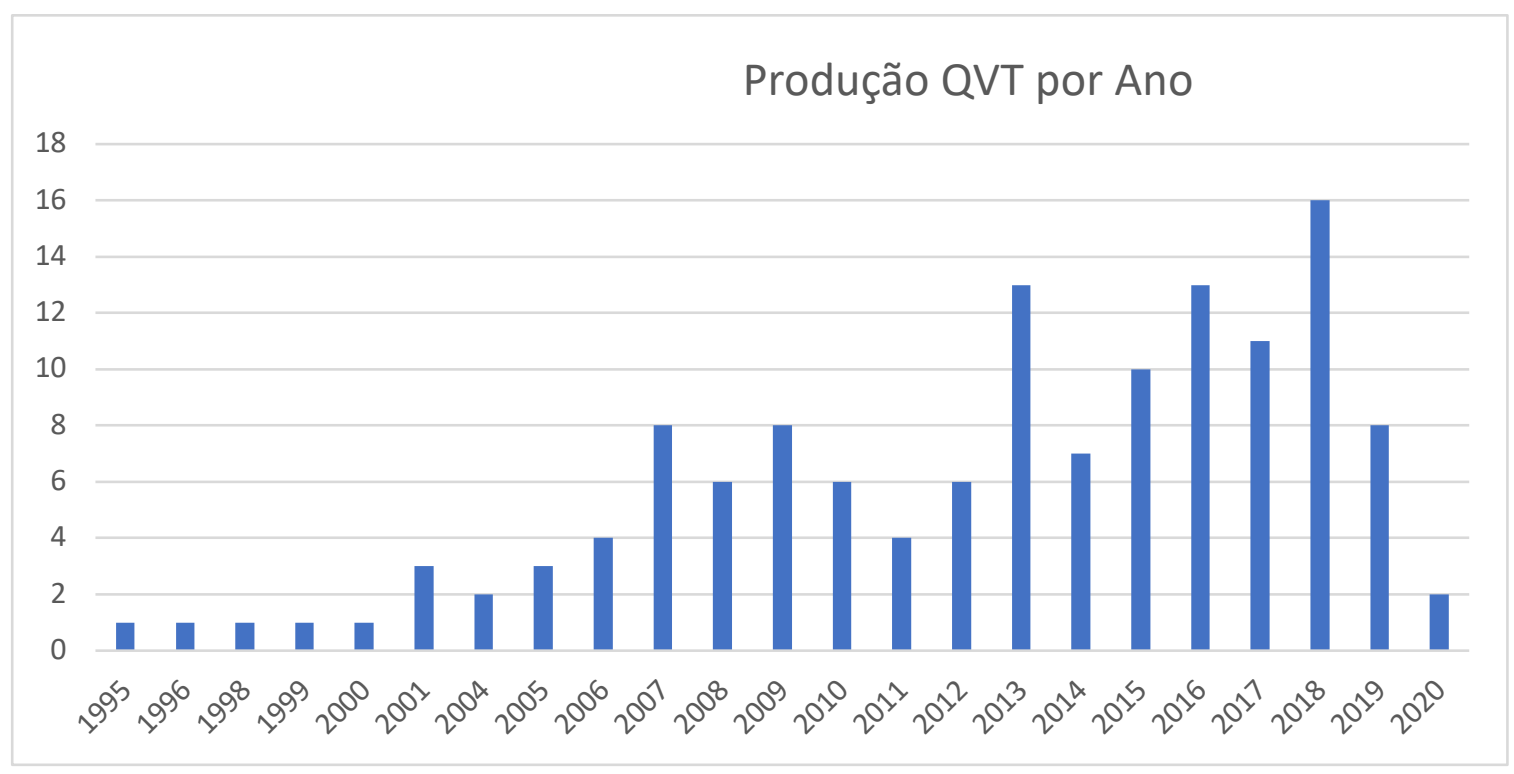

Fonte: Elaborado pelos autores

Nos anos de 1995, 1998, 1999 e 2000 houve a publicação de apenas um artigo por ano e, no período seguinte, a partir de 2001 as publicações começam a aumentar, no ano de 2012 são publicados seis artigos. A partir desse ano começam a se avolumar, com o pico no ano de 2018, com 16 artigos publicados. Esses dados possibilitam inferir que o tema QVT compõe a agenda de investigação dos centros de pesquisa.

Quanto ao tipo de pesquisa desenvolvido em 31 artigos, adotou-se a pesquisa qualitativa. Em três artigos foi utilizada a análise do discurso como meio de tratamento de dados, em um estudo foi utilizado o estudo etnográfico e em 28 artigos utilizou-se a análise de conteúdo para tratamento de dados e, consequentemente, atingindo os 
objetivos de pesquisa. Em 91 artigos, utilizou-se pesquisa quantitativa com aplicação de questionário. Para o tratamento dos dados, utilizou-se de análise estatística com as médias, moda, desvio padrão, análise fatorial e correlação para mensurar a aplicação do modelo ou validação das hipóteses de pesquisa. Nas pesquisas quantitativas, a predominância da aplicação do questionário de Walton (1973), seguido do instrumento de Limongi-França (2006). Com a aplicação de metodologia de pesquisa qualitativaquantitativa, são 13 artigos com tratamento de dados com análise de conteúdo das entrevistas semiestruturadas e análise estatística para os questionários. A análise do instrumento de coleta de dados permite inferir a influência que Walton (1973) exerce sobre a pesquisa nacional.

A maior parte dos artigos que compõem este estudo bibliométrico utilizou os critérios de Walton (1973) como parâmetro para investigar a QVT nos locais que conduziram as suas pesquisas, três artigos utilizaram o modelo de Hackman e Oldham (1974) e Limongi-França (1995), lidera a aplicação de modelos nacionais na amostra, com 16 artigos, utilizando o seu modelo para investigar a QVT nas organizações pesquisadas.

A análise dos artigos quanto ao instrumento de coleta de dados para validação dos objetivos de pesquisa, reforça o argumento de Rosalino e Bardagi (2008), que diz que a pesquisa nacional é fundamentada na literatura estrangeira. $\mathrm{Na}$ amostra analisada, dois artigos utilizam o modelo de Fernandes (1996), dezesseis utilizam o de LimongiFrança (2006) e os demais utilizam Walton (1973), Hackman e Oldhan (1975), Westley (1979) e Werther e Davis (1983).

O exame da amostra quanto ao número de vezes que o artigo foi citado demonstra que a literatura nacional tem sido utilizada. No quatro 3 é possível verificar que as citações de pesquisadores nacionais vêm aumentando de acordo com as pesquisas, que estão se expandido.

Quadro 3 - Número de vezes que o artigo foi citado

\begin{tabular}{|l|l|}
\hline Autores & $\begin{array}{l}\text { Número de } \\
\text { Citações }\end{array}$ \\
\hline Luz, SOUZA e SILVA (2011), (REIS NETO et al., 2015), & 0 \\
(GASPAR et al., 2013), (COURA et al., 2017), (SILVA, 2017), & \\
(MESQUITA et al., 2018), (GOMES et al., 2018), (VIEIRA et al., & \\
2018), (SOUZA et al., 2019), (LOUVEIRA; BRUSTOLIN; & \\
DERROSSO, 2018),(MILHOME; ROWE; SANTOS, 2018), & \\
\hline
\end{tabular}


(SANTOS, et al., 2019), (BOLDO; SEVERO; GUIMARÃES, 2019), (VITAL; PAIVA, 2019), (SOUZA et al., 2019), (FALCE et al., 2020).

(BELO; MORAES, 2007), (OLIVEIRA; MEDEIROS, 2008), 1 (MAIA; ARAÚJO; ALLOUFA, 2014), (PINTO; KEMMER; FILIPPIM, 2011), (BIAGINI; SILVA, 2015), (SÁ, 2015), (FERREIRA; VASCONCELOS, 2016), (MATIAS; MOURA, 2016), (MATTOS et al., 2017), (TIECHER; DIEHL, 2017), (VENELLI-COSTA et al., 2018), (LÍRIO; SEVERO; GUIMARÃES， 2018), (WILLEMANN; FERREIRA， 2018), (CORREIO; CORREIO; BARROS, 2019), (QUEIROZ et al., 2019), (ANDRADE; LIMONGI-FRANÇA; STEFANO, 2019).

(LIMA; JARDIM, 2013), (PANUCCI-FILHO; HEIN; KROENKE, 2 2017)), (PICOLLI; CASAGRANDE, 2017), (SANTOS; BORGES, 2018), (KLEIN; LEMOS; PEREIRA, 2018), (ANDRADE; LAAT; STEFANO, 2018).

(KANIKADAN et al., 2005), (SILVA JUNIOR et al., 2012), 3 (OLIVEIRA FILHO et al., 2013), (PIZZINATO; CARLOTTO; CÉ, 2014), (FELL; MARTINS, 2015), (ZANARDI et al., 2015), (FREITAS et al., 2016), (AYRES; NASCIMENTO; MACEDO, 2016), (COELHO et al., 2016), (DIAS et al., 2016), (PAIVA et al., 2017), (GARCIA, 2017), (PAIVA et al., 2017), (MARANHÃO; SÁ, 2019), (SILVA; VOLPATO; RONSANI, 2018), (ALVES; CORREIA; SILVA, 2019).

(DOURADO; CARVALHO, 2007), (LIMA; STEFANO; 4 ZAMPIER, 2011), (LEITE; TOMELIN; RAMOS, 2014), (ALFENAS; RUIZ, 2015), (ARAÚJO et al., 2016), (CERIBELI; CERIBELI; FERREIRA, 2016), (POZO; TACHIZAWA, 2016), (MILHOME; ROWE, 2016), (EL-AOUAR; VASCONCELOS; VEIGA NETO, 2016).

(BARROS; ARÁUJO; JOHANN, 2013), (COSTA et al., 2013), 5 (OLIVEIRA et al., 2013)

\begin{tabular}{|l|l}
\hline (PESSOA; NASCIMENTO, 2008), (GOMES et al., 2017) & 6
\end{tabular}

(GUIDELLI; BRESCIANI, 2008), (GARCIA, 2010), (OLIVEIRA 7 et al., 2015), (SOUZA; MAZINI FILHO, 2017)

(CHAGAS; MARQUES; BARROSO, 2005), (ROSALINO; 8 BARDAGI, 2008), (OLIVEIRA et al., 2015), (ZWIELEWSKI; TOLFO, 2016).

(OLIVEIRA; SILVA, 2015), (GARCIA, 2017)), (ARELLANO; 9 LIMONGI-FRANÇA, 2013)

(PEREIRA; SALLES; PASSOS, 2010), (PAIVA; AVELAR, 2011), 10 (FERREIRA; BRUSIQUESE, 2014), (OLIVEIRA, et al., 2015)

(GARCIA, 2007), (OLIVEIRA; MINETTI; OLIVEIRA, 2012)

Revista Eletrônica Gestão e Serviços v.12, n. 1, pp. 3382 - 3411, Janeiro/Junho 2021. ISSN Online: 2177-7284 e-mail: regs@metodista.br 


\begin{tabular}{|c|c|}
\hline (KANIKADAN; LIMONGI-FRANÇA, 2007), & 12 \\
\hline $\begin{array}{l}\text { (RECHZIEGEL; VANELLE, 1999), (SOUZA; MEDEIROS, 2007), } \\
\text { (OLIVEIRA, et al., 2013), (TODESCHINI; FERREIRA, 2013), }\end{array}$ & 13 \\
\hline (VASCONCELOS et al., 2012) & 14 \\
\hline (SOUZA; BASTOS, 2009) & 15 \\
\hline $\begin{array}{l}\text { (LIMONGI-FRANÇA; KANIKADAN, } \\
\text { BRESCIANI, 2006), }\end{array}$ & 16 \\
\hline $\begin{array}{lccc}\text { (MARQUES; } & \text { BORGES; } & \text { ADORNO, 2008), } & \text { (NESPECA; } \\
\text { CAVALLINI, 2011), (VILAS BOAS; MORIN, 2017) } & \end{array}$ & 17 \\
\hline $\begin{array}{l}\text { (VIEIRA, ADRIANE, 1996), (ASFORA; DIAS, 2006), (GRANDE } \\
\text { et al., 2013) }\end{array}$ & $\underline{18}$ \\
\hline (ABREU; MORAES, 2012), (MEDEIROS; OLIVEIRA, 2009) & 19 \\
\hline $\begin{array}{lccl}\text { (REGIS FILHO; LOPES, 2001), } & \text { (CARVALHO-FREITAS; } \\
\text { MARQUES; ALMEIDA, 2009) } & \end{array}$ & 21 \\
\hline (STEFANO et al., 2006), (VENSON et al., 2013) & 22 \\
\hline (NASCIMENTO; PESSOA, 2007) & 23 \\
\hline (KIMURA; CARANDINA, 2009) & 24 \\
\hline $\begin{array}{l}\text { (FERNANDES; FERREIRA, 2015), (VILAS BOAS; MORIN, } \\
\text { 2016) }\end{array}$ & 25 \\
\hline $\begin{array}{l}\text { (SOUZA; FIGUEIREDO, 2004), (DAVID, 2007), (BOTH et al., } \\
\text { 2010) }\end{array}$ & 26 \\
\hline (PIZZIO; KLEIN, 2015) & 28 \\
\hline $\begin{array}{l}\text { (CARNEIRO; FERREIRA, 2007), (LEITE; FERREIRA; MENDES, } \\
\text { 2009), }\end{array}$ & 29 \\
\hline (DOURADO; CARVALHO, 2006) & 31 \\
\hline (SCHMIDT; DANTAS; MARZIALE, 2008), (AMORIM, 2010) & 32 \\
\hline (LEITE; NASCIMENTO; OLIVEIRA, 2014) & 39 \\
\hline (SCHIRRMEISTER; LIMONGI-FRANÇA, 2012) & 44 \\
\hline (LIMONGI; ASSIS, 1995) & 45 \\
\hline (SILVA; TOLFO, 2012) & 56 \\
\hline (SILVA; FERREIRA, 2013) & 64 \\
\hline (SCHMIDT et al., 2013) & 71 \\
\hline (TIMOSSI et al., 2009) & 78 \\
\hline (FERREIRA et al., 2009) & 80 \\
\hline (MONACO; GUIMARÃES, 2000) & 84 \\
\hline (ROCHA; FELLI, 2004) & 110 \\
\hline
\end{tabular}

Revista Eletrônica Gestão e Serviços v.12, n. 1, pp. 3382 - 3411, Janeiro/Junho 2021. ISSN Online: 2177-7284 e-mail: regs@metodista.br 


\begin{tabular}{|l|l|}
\hline (OLIVEIRA; LIMONGI-FRANÇA, 2005) & 114 \\
\hline (TOLFO; PICCININI, 2001) & 119 \\
\hline (FERREIRA; ALVES; TOSTES, 2009) & 160 \\
\hline (ALBURQUERQUE; LIMONGI-FRANÇA, 1998) & 290 \\
\hline
\end{tabular}

Fonte: Elaborado pelos autores a partir dos trabalhos que compõe o estudo

O quadro 3 apresenta os artigos que compõem esta amostra com número de vezes que foram citados por outros trabalhos. Na próxima sessão são discutidos os resultados encontrados nessa amostra.

\section{DISCUSSÕES DOS RESULTADOS}

Os trabalhos que foram mais referenciados foram desenvolvidos em 1998 (ALBURQUERQUE; LIMONGI-FRANÇA, 1998). Neste trabalho, os autores têm o objetivo de verificar a influência da adoção da Qualidade Total e a interferência, participação do estresse nos programas de QVT, e, a partir desse momento, o conceito de QVT começaria a ganhar força no contexto organizacional. O segundo trabalho desenvolvido em 2009 pesquisa a percepção dos problemas de gestão junto aos dos serviços públicos (FERREIRA; ALVES; TOSTES, 2009). O trabalho de Rocha e Felli (2004) estuda o estilo de vida dos docentes de enfermagem com 110 citações. A pesquisa conduzida em 2000 com empregados da Empresa de Correios investiga os impactos da implantação do Programa de Qualidade Total e seus efeitos na QVT com 84 citações (MONACO; GUIMARÃES, 2000). O outro trabalho foi conduzido em 2009 para validar o instrumento de coleta de dados de Walton, com 78 citações (TIMOSSI et al., 2009).

A professora Limongi-França é a mais referenciada na soma de citações, com um total de 465, seguida pela professora Tolfo, com 171 citações com dois artigos, sendo um de 2001 e outro de 2012, e o professor Mario César Ferreira, com 160 citações com o artigo de 2009. No gráfico 2 é possível ver a rede a influência dos principais pesquisadores.

Gráfico 2 - Núcleo dos Autores 
oliveira, rodrigo ribeiro de

castro, dagmar silva pinto

alburquerque, lindolfo galvão

gattai, maria cristina pinto

arellano, eliete bernal

frança, ana cristina limongi

limongi-frança, ana cristina

kanikadan, andréa yumi sugishi

bose, monica

oliveira, patrícja morilha de

stefano, silvio roberto

coutinho, maria lúcia granja

\section{VOSviewer}

Gráfico elaborado pelos autores utilizando o Software Vosviewer

No gráfico 2 é possível verificar, que nesta amostra de artigos, a professora Limongi-França se encontra no núcleo central de influência, trazendo a sua contribuição para os demais centros de pesquisa e é possível inferir quais são os autores que são referências em cada centro de pesquisa. O gráfico 3 traz a evolução das publicações ao longo dos anos.

O gráfico 3 - Quantidade de citações por ano.

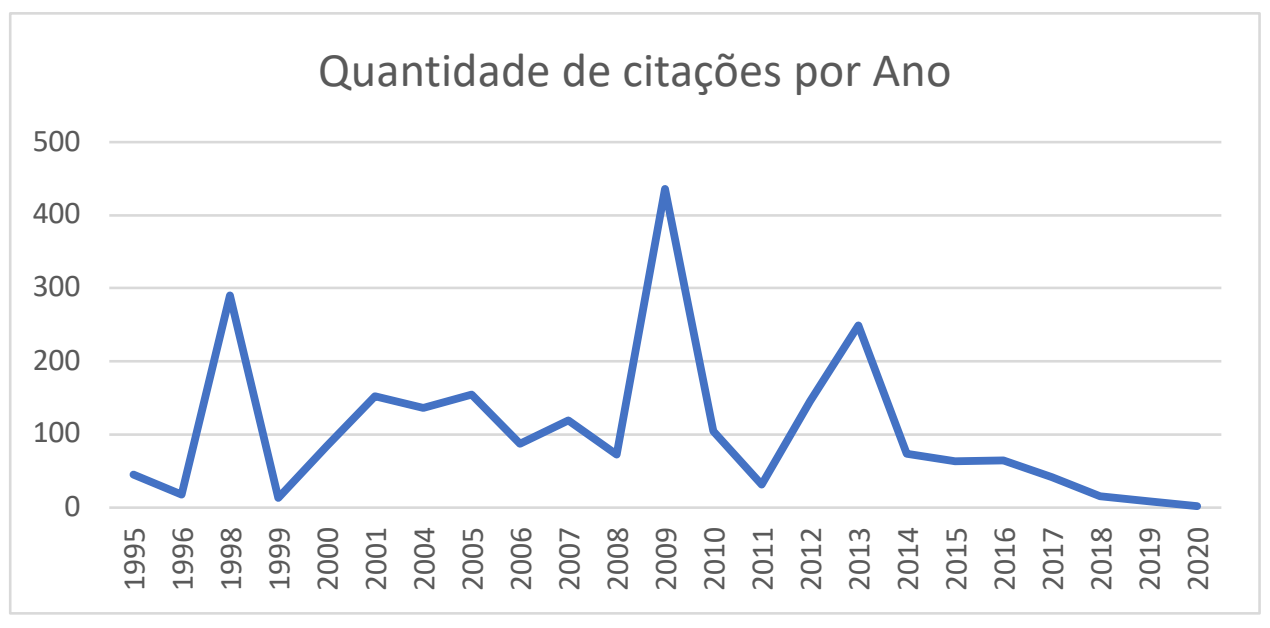

FONTE: produção dos autores a partir do trabalho que compõe a amostra.

Revista Eletrônica Gestão e Serviços v.12, n. 1, pp. 3382 - 3411, Janeiro/Junho 2021.

ISSN Online: 2177-7284 e-mail: regs@metodista.br 
O gráfico 3 permite verificar que os trabalhos anteriores a 2010 estão em menor proporção, mas são os mais citados ao longo dos anos, o que possibilita inferir que são os marcos teóricos do tema dentro da literatura de QVT nas bases pesquisadas. O artigo mais citado é a pesquisa realizada em 1998 por Albuquerque e Limongi-França sobre o estresse e a expansão do conceito de Qualidade Total. O pico no ano de 2009 refere-se a três artigos com 318 citações (FERREIRA; ALVES; TOSTES, 2009; FERREIRA et al., 2009; TIMOSSI et al., 2009)

O tema QVT, nesta amostra, encontra-se consolidado nos centros de pesquisas do Sudeste e Sul. Nas demais regiões o tema está em desenvolvimento no Centro-Oeste, Nordeste e Norte as publicações são recentes, para elucidar a situação, a região Norte são treze publicações com um total de 47 citações. O gráfico 4 retrata a demografia da pesquisa em QVT no país.

Gráfico 4: Produção científica em QTV por região

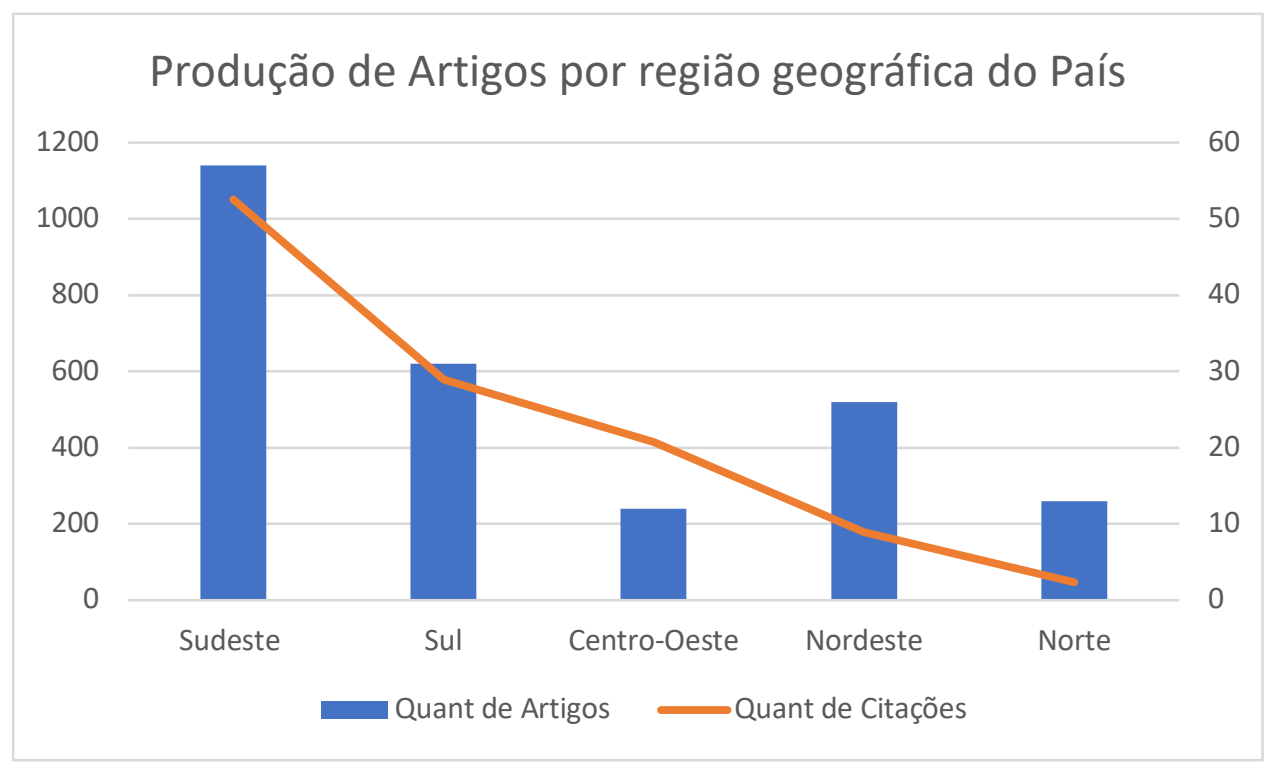

Fonte: produção dos autores a partir dos dados da pesquisa

A região Sudeste conta com 57 artigos, tendo um total de 1051 citações, concentrando a produção na Universidade de São Paulo (OLIVEIRA; LIMONGIFRANÇA, 2005; ROCHA; FELLI, 2004), a região Sul são 31 artigos com um total de 579 citações a e Universidade de Santa Catarina lidera o ranking (TIMOSSI et al., 2009; TOLFO; PICCININI, 2001). Na região Centro-Oeste são 12 artigos com 414 citações a produção se concentra na Universidade de Brasília (FERREIRA; ALVES; 
TOSTES, 2009). Na região Nordeste são 26 artigos com 179 citações, a Universidade Federal do Rio Grande do Norte (MEDEIROS; OLIVEIRA, 2009; SOUZA; MEDEIROS, 2007) são os estudos que sobressaem sobre os demais. Na região Norte com 13 artigos são 47 citações e o destaque é o estudo (OLIVARES; BONITO; SILVA, 2015) conduzido junto ao programa de atenção as famílias no Estado de Roraima com atenção a QVT dos médicos com 12 citações.

A inferência destes dados possibilita verificar que os estudos nas regiões Sudeste, Sul estão consolidados com pesquisadores mais experientes. As regiões Centro-Oeste, Norte e Nordeste iniciaram suas publicações nesta área a partir de 2005 (CHAGAS; MARQUES; BARROSO, 2005) e 2011 (LUZ; SOUZA; SILVA, 2011) junto com a intensificação e a expansão Institutos Federais (FERNANDES, 2009).

A investigação de como o Comprometimento Organizacional influencia a QVT é objeto de estudo em cinco artigos (CARVALHO-FREITAS; MARQUES; ALMEIDA, 2009; LÍRIO; SEVERO; GUIMARÃES, 2018; PANUCCI-FILHO; HEIN; KROENKE, 2017; SCHIRRMEISTER; LIMONGI-FRANÇA, 2012; ZANARDI et al., 2015). Os achados dos estudos evidenciam a influência positiva das ações de QVT, principalmente no comprometimento afetivo (LÍRIO et al 2018; PANUCCI-FILHO et al 2017), este comportamento é ratificado nos estudos com pessoas com deficiência física (CARVALHO-FREITAS; MARQUES; ALMEIDA, 2009). As conclusões que os estudos apontam que os investimentos em QVT influenciam no comprometimento organizacional, principalmente no comprometimento afetivo que dentro das considerações de Meyer e Allen (1990) é o melhor para a organização (SILVA; FERREIRA, 2013).

Em aos docentes de enfermagem em escolas públicas, os trabalhos que focam a QVT, que compõem a essa amostra, relatam que o trabalho é considerado estressante, que normalmente os docentes atuam em dois locais de trabalho diferentes. Estes profissionais enfrentam uma dupla jornada comprometendo a sua qualidade de vida (GOMES et al., 2017; KIMURA; CARANDINA, 2009). Os docentes buscam outro turno de trabalho para melhorarem os seus rendimentos. A partir desses achados é possível inferir que a insatisfação com a remuneração leva estes trabalhadores a se exaurirem em uma dupla jornada, correndo o risco de adoecimento para complementar a sua renda.

Os estudos conduzidos em organizações, de natureza pública, evidenciam 
insatisfação com que as dimensões remuneração e benefícios, principalmente com a política adotada pela administração, que na amostra, são a maioria dos artigos. A solução apontada para melhorar este índice passa pela construção de uma política de remuneração adequada à função, e priorização da manutenção de um plano de carreira condizentes com as funções ocupadas (BOTH et al., 2010; NASCIMENTO, 2016). No aspecto remuneração para o funcionalismo público, os gestores programas de QVT devem ter em mente, que as alterações nesse item dependem de margem no teto de gasto do governo. A administração pública se encontra limitada com relação aos gastos com a remuneração do funcionalismo pela Lei de Responsabilidade Fiscal (BRASIL, 2002). Para melhorar a percepção dos servidores, deverá buscar alternativas sem ferir os parâmetros estabelecidos na referida lei.

A dimensão da participação na tomada de decisão apresenta índice com baixo grau de satisfação, pois os servidores desejam maior autonomia na tomada de decisão. Os gestores devem buscar alternativas para que os servidores possam participar ativamente das tomadas de decisões para se sentirem valorizados. Os trabalhos realizados no poder judiciário (FERNANDES; FERREIRA, 2015) apresentam de índice insatisfação com a organização do trabalho/distribuição do trabalho. As inferências dos achados permitem concluir que a administração pública deveria fazer uma melhor gestão dessa dimensão no intuito de melhorar a percepção dos servidores com relação a estas dimensões, no poder Judiciário buscar melhorar a organização e distribuição do trabalho entre os servidores para reduzir a sobrecarga consequente o adoecimento.

As pesquisas conduzidas nas empresas privadas são 24 , e os resultados permitem inferir que em relação a QVT, igualmente aos estudos conduzidos no setor público, há uma parcela de trabalhadores insatisfeita com a dimensão remuneração e premiação, autonomia e participação no processo decisório (COSTA et al., 2013; GUIDELLI; BRESCIANI, 2010). No setor privado existem indivíduos satisfeitos com as condições de trabalho, se sentem bem remunerados, valorizados, úteis e beneficiados. Sentimentos esses que não encontram no trabalho doméstico, tido como uma obrigação, um trabalho invisível que ninguém valoriza e que não traz recompensas (CHAGAS; MARQUES; BARROSO, 2005). As influências da ergonomia foram aferidas em alguns estudos que constataram que a organização do trabalho pela liderança é reivindicação dos subordinados, sendo a insatisfação motivo de estresse e adoecimento (PEREIRA; SALLES; PASSOS, 2010; ROCHA; FELLI, 2004). As conclusões que chegam os 
estudos, é de que o tema QVT, nas empresas privadas, tem nuances próprias em cada empresa de acordo com a cultura organizacional, política de gestão de QVT e com o perfil do indivíduo que nelas atua (KIMURA; CARANDINA, 2009; PANUCCIFILHO; HEIN; KROENKE, 2017; WILLEMANN; FERREIRA, 2018). No estudo de Chagas et al (2005) os indivíduos se sentem satisfeitos com as condições de trabalho, mesmo expostos a altas cargas de estresse para conciliar vida profissional e pessoal, o trabalho representa para estes indivíduos a seu direito de cidadania.

\section{Considerações Finais}

O bem-estar no trabalho abrange várias dimensões, de acordo com Oliveira e Limongi-França (2005), desde o biológico, psicológico, social e organizacional. Para que o indivíduo esteja produtivo, se faz necessário um equilíbrio entre essas dimensões. $\mathrm{Na}$ busca de aferir este bem-estar, métodos foram desenvolvidos.

Os estudos que compõem esta amostra possibilitaram concluir que o tema QVT está presente nas organizações brasileiras, em algumas de forma incipiente, em algumas (COSTA et al., 2013), e em outras, já está consolidado (TOLFO; PICCININI, 2001). Os artigos se concentram em avaliar a QVT nas empresas da administração pública, apontando um certo nível de insatisfação com a dimensão salarial e premiação, autonomia e participação no processo decisório. Os gestores de QVT devem compensar a insatisfação com a política de remuneração na área pública com a utilização de outros artifícios, uma vez que a remuneração e as premiações são limitadas pelo teto de gastos pela Lei de Responsabilidade Fiscal (BRASIL, 2002). Os pesquisadores apresentaram sugestões para os gestores buscarem meios para melhorar esses índices nas demais dimensões, em que o funcionalismo público não está muito satisfeito, com QVT, mas que permitem implementar soluções que não expandem os gastos públicos, como organização do trabalho, participação no processo de decisão. Os trabalhos realizados no poder judiciário (FERNANDES, LÍVIA CAROLINA; FERREIRA, 2015) apresentam índice de insatisfação com a organização do trabalho. Como sugestão de melhoria, os autores, sugerem que os gestores busquem melhorar este critério para reduzir o nível de estresses, e consequente adoecimento dos servidores.

Para as empresas privadas, o bem-estar no trabalho é satisfatório para indivíduos que veem no trabalho a realização de sua cidadania, são os resultados apontados nas pesquisas realizadas com mulheres e pessoas com deficiência (CARVALHO-FREITAS; 
MARQUES; ALMEIDA, 2009; CHAGAS; MARQUES; BARROSO, 2005). Quanto aos demais entrevistados os estudos evidenciam, que as categorias de remuneração e premiação, a autonomia e participação no processo decisório, apresentam índices de insatisfação. Há relatos de sobrecarga de trabalho que pode causar estresses e adoecimento (COSTA et al., 2013; GUIDELLI; BRESCIANI, 2010; ROCHA; FELLI, 2004). Nesses casos os autores sugerem que os gestores devem tomar medidas a fim de melhorar a percepção dos trabalhadores em relação as categorias que apresentam resultados deficitários, como melhoria na participação do processo decisório, e elaboração de um plano de cargo e salários.

Conclui-se que a tema QVT está presente nas empresas privadas e na administração pública, o nível de satisfação dos entrevistados, de acordo com os achados é satisfatório. As minorias apresentam um nível bom de satisfação com a QVT de suas organizações. Nesse caso são as mulheres, que estão felizes por expressarem a sua cidadania com o trabalho que exercem. Indiferente das condições estressantes que estão submetidas, na rotina laboral e pessoal. Existe um nível de insatisfação tanto na esfera pública quanto privada quanto à dimensão remuneração e premiação, autonomia e tomada de decisão e organização do trabalho praticada pela liderança, o que pode causar sobrecarga de trabalho e consequentemente o adoecimento. Nas pesquisas com docentes e profissionais da saúde, é possível verificar que sua qualidade de vida é comprometida com a existência de um segundo emprego, ou seja, o indivíduo se submete a uma dupla jornada para complementar a sua renda, em consequência desse maior esforço, vir a adoecer. De acordo com os resultados apresentados pelos artigos, que compõem esta amostra, a QVT proporciona bem-estar ao indivíduo que melhora a sua produtividade, diminui ou elimina o absenteísmo, reduz o adoecimento, a rotatividade, assim a organização deveria adotar práticas que melhore o bem-estar do colaborador no seu ambiente de trabalho. Assim, todos ganhariam com essas medidas.

As limitações da pesquisa se referem ao fato de apenas três Bases de Dados terem sido consultadas. Os Periódicos da CAPES, Ebsco Host e SPELL, possuem livre acesso, enquanto outras bases possuem limitação de acesso público.

Como sugestões de pesquisas futuras, propomos ampliar a investigação para mais bases de publicação e focar nos estudos em que o tema QVT esteja relacionado a outros construtos, tais como cultura organizacional, comprometimento organizacional e implementação de instrumentos de mensuração de QVT. 


\section{Referencial}

ABREU, Márcia Viana De; MORAES, Lucio Flávio Renault De. A Qualidade de Vida no Trabalho de Pessoas com Deficiência: Um Estudo de Caso de Uma Grande Empresa do Setor Metalúrgico. Revista Eletronica de Gestão Organizacional, v. 10, n. 1, p. 21 , 2012 .

ALBURQUERQUE, Lindolfo Galvão De; LIMONGI-FRANÇA, Ana Cristina. Estrategias de Recursos Humanos e Gestão da qualidde de vida no trabalho: o stress e a expanão do conceito de Qualidade Total. Revista de Administração, v. 33, p. 40-51, 1998.

ALFENAS, R.A.S.; RUIZ, V.M. Um Panorama de Estudos Sobre Qualidade de Vida no Trabalho na Administração Pública Brasileira no Período de 2007 a 2013. Revista Organizações em Contexto, v. 11, n. 22, p. 143-167, 30 dez. 2015.

ALLEN, N. J.; MEYER, J. P >. The measurement and antecedents of affective, continuance and normative commitment to the organization. Journal of Occupational Psychology, v. 63, p. 1-18, 1990.

ALVES, Cinthya Rafaela Araújo; CORREIA, Ana Maria Magalhães; SILVA, Armistrong Martins Da. Qualidade de vida no trabalho (QVT): um estudo em uma instituição federal de ensino superior. Revista Gestão Universitária na América Latina GUAL, v. 12, n. 1, p. 205-227, 2 jan. 2019.

AMORIM, Tania Gonçalves Ferreira Nobre. Qualidade de Vida no Tabalho: preocupação também para servidores públicos? RECADM, v. 9, p. 35-48, 2010.

ANDRADE, Sandra Mara de; LIMONGI-FRANÇA, Ana Cristina; STEFANO, Silvio Roberto. Dimensões da qualidade de vida no trabalho e justiça organizacional: um estudo com servidores públicos municipais Dimensions of quality work life and organizational justice: a case with municipal public servants. Revista Capital Científico - Eletrônica (RCCee) - ISSN 2177-4153, v. 17, n. 3, p. 93-108, 1 jul. 2019.

ANDRADE, Luciana Bortoncello Lorenzetti; LAAT, Erivelton Fontana De; STEFANO, Silvio Roberto. Quality of Life at Work and Commitment of Public School Principals. Revista Eletrônica de Ciência Administrativa, v. 17, n. 1, p. 54-83, 18 mar. 2018.

ARAÚJO, Paulo César Diniz de et al. Avaliação sobre Qualidade de Vida no Trabalho entre os docentes de duas Instituições de Ensino Superior: uma realidade no Estado do Amazonas. Gestão e Sociedade, v. 9, n. 23, p. 961, 28 mar. 2016.

ARELLANO, Eliete Bernal; LIMONGI-FRANÇA, Ana Cristina. Análise crítica dos indicadores dos programas de qualidade de vida no trabalho no Brasil. O Mundo da Saúde, v. 37, n. 2, p. 141-151, 30 jun. 2013.

ASFORA, Silvia Cauás; DIAS, Sônia Maria Rodrigues Calado. MODELO DE QUALIDADE DE VIDA NO TRABALHO PARA POLÍCIA MILITAR DE PERNAMBUCO. v. 12, n. 49, p. 90-114, 2006.

AYRES, Rosângela M; NASCIMENTO, João Carlos Hipólito Bernardes Do; MACEDO, Marcelo Álvaro da S. Satisfação do Profissional de Contabilidade do Estado do Rio de Janeiro quanto à Qualidade de Vida no Trabalho - QVT (2014-2015): Uma 
Análise por PLS-SEM com base no Modelo Dimensional de Walton. v. 18, n. 67, p. 10, 2016.

BARROS, Maria Mércia dos Santos; ARÁUJO, Marley Rosana Melo; JOHANN, Rejane Lúcia Veira Oliveira. O cuidador merece cuidado: estudo sobre qualidade de vida em profissionais de saúde mental. Revista de Psicologia e Saude, Revista Psicologia e Saúde. v. 5, p. 32-39, jun. 2013.

BELO, Ione de Faria; MORAES, Lúcio Flávio Renault de. A qualidade de vida no trabalho de desembargadores e juízes da comarca de Belo Horizonte: estudo de casos. p. 20, 2007.

BIAGINI, Angelo Piva; SILVA, Gabriel Pádua da. Nível de Qualidade de Vida no Trabalho de Colaboradores de Uma Clínica Geriátrica. Revista de Gestão em Sistemas de Saúde - RGSS, v. 4, p. 51-56, 2015.

BOLDO, Tayna; SEVERO, Eliana Andréa; GUIMARÃES, Júlio Cesar Ferro de. Responsabilidade Social e Qualidade de Vida no Trabalho: A Percepção de Funcionários Supermercadistas. REUNA, v. 23, n. 4, p. 62-82, 30 maio 2019.

BOTH, J et al. Condições de vida do trabalhador docente: Associação entre estilo de vida e qualidade de vida no trabalho de professores de Educação Física. Motricidade, v. 6, p. 39-51, 2010.

BRASIL. Lei de responsabilidade fiscal: lei complementar no. 101, de 4 de maio de 2000. Brasília: Senado Federal, Subsecretaria de Edições Técnicas, 2002.

CARNEIRO, Thiago Lopes; FERREIRA, Mário César. Redução de jornada melhora a qualidade de vida no trabalho? A experiência de uma organização pública brasileira. Revista Psicologia: Organizações e Trabalho, v. 7, p. 27, 2007.

CARVALHO-FREITAS, Maria Nivalda; MARQUES, Antônio Luiz; ALMEIDA, Luciana A. D, de. Pessoas com Deficiência: Comprometimento Organizacional, Condições de Trabalho e Qualidade de Vida no Trabalho. v. 2, p. 14, 2009.

CAVEDON, Neusa Rolita. A qualidade de vida no trabalho na área da Segurança Pública: uma perspectiva diacrônica das percepções olfativas e suas implicações na saúde dos servidores. Organizações \& Sociedade, v. 21, n. 68, p. 875-982, mar. 2014.

CERIBELI, Harrison Bachion; CERIBELI, Maria Cláudia Bachion; FERREIRA, Fábio José Rodrigues. Análise da Qualidade de Vida no Trabalho (QVT) Sob a Perspectiva das Diferenças Entre Gêneros. REUNA, v. 21, n. 3, p. 5-24, 30 set. 2016.

CHAGAS, Maristela Inês Osawa; MARQUES, Maria de Fátima Cardoso; BARROSO, Maria Grasiela Teixeira. Mulheres operárias: vida doméstica e qualidade de vida. Revista Brasileira em Promoção da Saúde, p. 130-135, 2005.

COELHO, Eduardo et al. Autoeficácia e Qualidade de Vida no Trabalho: um estudo com policiais militares. Psicologia: Teoria e Pesquisa, v. 32, 2016.

CORREIO, Eduardo Novais Almeida; CORREIO, Letícia Giotti; BARROS, Adriano David. Análise da qualidade de vida no trabalho em uma instituição pública de ensino. Revista de Carreiras e Pessoas (ReCaPe) |ISSN-e: 2237-1427, v. 9, n. 3, 2 set. 2019.

COSTA, Cleber Aparecido da et al. Qualidade De Vida No Trabalho, Satisfação E Motivação Do Trabalhador No Setor De Varejo. QUALITY OF LIFE, THE EMPLOYEE 
MOTIVATION AND SATISFACTION IN RETAIL SECTOR., v. 11, n. 1, p. 181-198, maio 2013.

COURA, Alessandro Silva et al. Fatores sociodemográficos associados à qualidade de vida no trabalho de adultos com deficiência física. Revista Brasileira de Medicina do Trabalho, v. 15, n. 3, p. 229-235, 2017.

COUTINHO, Maria Lúcia Granja; MAXIMIANO, Antônio Cesar Amaru; LIMONGIFRANÇA, Ana Cristina. Implantação de Programas de Qualidade de Vida no Trabalho com Modelo de Gestão de Projetos. Revista de Gestão e Projetos, v. 1, n. 1, p. 172-189, 2010 .

DAVID, Lamartine Moreira Lima; BRUNO-FARIA, Maria de Fátima. Qualidade de vida no trabalho: construção e validação de uma escala em organizações militares do Exército. Revista de Administração, p. 12, 2007.

DIAS, Ernandes Gonçalves et al. Calidad de vida en el trabajo de los profesionales de salud de una Unidad Básica de salud. Revista Cubana de Enfermería., v. 32, p. 12, 2016.

DOURADO, Débora Coutinho Paschoal; CARVALHO, Cristina Amélia. Controle do homem no trabalho ou qualidade de vida no trabalho? Cardernos EBAPE, v. 4, p. 15, 2006.

DOURADO, Débora Coutinho Paschoal; CARVALHO, Cristina Amélia. Extra! Extra! O caso do Metrorec revela como é operada a manipulação ideológica do discurso da QVT. Cadernos EBAPE.BR, v. 5, n. 4, p. 01-03, dez. 2007.

EL-AOUAR, Walid Abbas; VASCONCELOS, César Ricardo Maia De; VEIGA NETO, Alipio Ramos. Quality of working life and music in the manufacturing workplace.

Organizações \& Sociedade, v. 23, n. 79, p. 656-674, dez. 2016.

FALCE, Jefferson Lopes La et al. Calidad de Vida en el Trabajo y Actividad Física: Estudio em Uma Institución Federal de Educación. REVISTA ALCANCE, v. 27, n. 1, p. 15,2020 .

FELL, André Felipe de Albuquerque; MARTINS, Daniel Felipe Victor. Memória Sobre a Qualidade de Vida no Trabalho (QVT): Uma Perspectiva Crítica. Perspectivas em Gestão \& Conhecimento, v. 5, p. 35-48, 2015.

FERNANDES, Eda. Qualidade de Vida no Trabalho. Bahia: CASA DA QUALIDADE, 1996.

FERNANDES, Francisco das Chagas Mariz. Gestão dos Institutos Federais: O Desafio do Centenário da Rede Federal de Educação Profissional e Tecnológica. HOLOS, v. 2, p. 3,14 out. 2009.

FERNANDES, Lívia Carolina; FERREIRA, Mário César. Qualidade de vida no trabalho e risco de adoecimento: estudo no poder judiciário brasileiro. Psicologia USP, v. 26, n. 2, p. 296-306, ago. 2015.

FERREIRA, Cláudia Aparecida Avelar; VASCONCELOS, Fernanda Carla Wasner. Diálogo entre Gestores e Trabalhadores da Saúde Mental sobre a Qualidade de Vida no Trabalho: É Possível? Gestão \&Conexões Managemente an Connections Journal, v. 5, p. $90-120,2016$. 
FERREIRA, Mário César; ALVES, Luciana; TOSTES, Natalia. Gestão de Qualidade de Vida no Trabalho (QVT) no serviço público federal: o descompasso entre problemas e práticas gerenciais. Psicologia: Teoria e Pesquisa, v. 25, n. 3, p. 319-327, set. 2009.

FERREIRA, Mário César; BRUSIQUESE, Romildo Garcia. Novas condições de trabalho e velhos modos de gestão: a qualidade de vida no trabalho em questão. Revista Brasileira de Gestão e Desenvolvimento Regional Revista Brasileira de Gestão e Desenvolvimento Regional, v. 10, p. 247-67, 2014.

FERREIRA, Rodrigo R et al. Concepção e implantação de um programa de qualidade de vida no trabalho no setor público: o papel estratégico dos gestores. RAUSP, p. 11, 2009.

FREITAS, Artur Juvêncio De et al. Qualidade de Vida no Trabalho e Saúde e Segurança Ocupacional em Uma Organização da Construção Civil. RGO REVISTA GESTÃO ORGANIZACIONAL, v. 9, p. 20, 2016.

GARCIA, Edilene de Oliveira Pereira. Estudo de Caso Exploratório sobre Qualidade de Vida no Trabalho de Funcionários Públicos. Revista Organizações em Contexto, v. 5, p. 9-31, 30 jun. 2007.

GARCIA, Edilene de Oliveira Pereira. O Conteúdo Significativo da Qualidade de Vida no Trabalho para Funcionários Públicos de uma Secretaria de Saúde. Revista Eletrônica Gestão e Serviços, v. 1, n. 1, p. 76-94, 30 jun. 2010.

GARCIA, Ysrael Moura. Qualidade de Vida no Trabalho segundo a percepção dos técnicos administrativos do Instituto Federal de Educação, Ciência e Tecnologia do Ceará (IFCE). Organizações em contexto, v. 13, p. 20, 2017.

GASPAR, Marcos Antônio et al. Qualidade de vida no trabalho para pessoas com deficiências: estudo de caso numa montadora de automóveis. RECAPE, p. 17, 2013.

GOMES, Khayas Karla et al. Qualidade de Vida e Qualidade de Vida no Trabalho em docentes da saúde de uma instituição de ensino superior. Rev Bras Med Trab., p. 18-18, 2017.

GOMES, Maria José de Figueiredo et al. Conceito de qualidade de vida no trabalho na diversidade dos campi do IFRN. Revista Principia - Divulgação Científica e

Tecnológica do IFPB, v. 1, n. 38, p. 120, 15 fev. 2018.

GOULART, I.B. e Sampaio, J.R. Qualidade de vida no trabalho e psicologia social. Casa do Psicólogo Editora, 2004, p. 27 e 28

GRANDE, Antônio José et al. Determinantes da qualidade de vida no trabalho: ensaio clínico controlado e randomizado por clusters. Revista Brasileira de Medicina do Esporte, v. 19, n. 5, p. 371-375, out. 2013.

GUIDELLI, Nilo Sergio; BRESCIANI, Luis Paulo. Inovação e qualidade de vida no trabalho: uma visão integrada da gestão a partir de estudo de caso na indústria petroquímica do Grande ABC. Revista de Administração, v. 45, p. 57-69, jan. 2010.

GUIDELLI, Nilo Sergio; BRESCIANI, Luis Paulo. Qualidade de Vida no Trabalho e Ambiente de Inovação: encontros e desencontros no serviço de atendimento ao cliente. Revista Brasileira de Inovação, v. 7, n. 2, p. 341-365, 2008. 
HACKMAN, J. Richard; OLDHAM, Greg R. The Job Diagnostic Survey: An Instrument for the Diagnosis of Jobs and the Evaluation of Job Redesign Projects. [S.1: s.n.], 1974.

HUSE, E. \& CUMMINGS, T. Organization development and change. Minn:West Publishing, 1985

KANIKADAN, Andréa Yumi Sugishita et al. Gestão da Qualidade de Vida no Trabalho e Estratégia Empresarial: Estudo de Caso na Empresa X. p. 14, 2005.

KANIKADAN, Andréa Yumi Sugishita; LIMONGI-FRANÇA, Ana Cristina. A Qualidade de Vida no Trabalho dos Professores de Inglês. São Paulo, v. 9, n. 25, p. 22, 2007.

KIMURA, Miako; CARANDINA, Dirley Maria. Desenvolvimento e validação de uma versão reduzida do instrumento para avaliação da Qualidade de Vida no Trabalho de enfermeiros em hospitais. Revista da Escola de Enfermagem da USP, v. 43, p. 1044 1054, dez. 2009.

KLEIN, Leander Luiz; LEMOS, Ricardo Brião; PEREIRA, Breno. Qualidade de Vida no Trabalho: Parâmetros e Avaliação no Serviço Público. In: ENEGEP 2018 ENCONTRO NACIONAL DE ENGENHARIA DE PRODUÇÃO, 15 nov. 2018, MACEIO/AL - BRASIL. Anais... MACEIO/AL - BRASIL: [s.n.], 15 nov. 2018.

LEITE, Denise Fernandes; NASCIMENTO, Débora Dupas Gonçalves Do; OLIVEIRA, Maria Amélia de Campos. profissionais do NASF no município de São Paulo. Physis Revista de Saúde Coletiva, v. 24, p. 19, 2014.

LEITE, José Vieira; FERREIRA, Mário César; MENDES, Ana Magnólia. Mudando a Gestão da Qualidade de Vida no Trabalho. Revista Psicologia: Organizações e Trabalho, v. 2, p. 109-123, 2009.

LEITE, Marcus Henrique Rolim; TOMELIN, Carlos Alberto; RAMOS, Marcos Roberto. Bastidores da hotelaria: qualidade de vida no trabalho no setor de governança - camareiras dos hotéis de Foz do Iguaçu - PR - Brasil. Management Studies, p. 7, 2014.

LIMA, Amanda Caico Collares De; STEFANO, Silvio Roberto; ZAMPIER, Maria Aparecida. Satisfação da Qualidade de Vida no Trabalho dos Professores de Arte da Rede Escolar no Interior do Paraná. Revista Capital Científico, v. 9, 2011.

LIMA, Luana Almeida; JARDIM, Gardênia Tereza Pereira. Motivação e qualidade de vida no trabalho: uma análise na Comagro Peças e Serviços LTDA. Rev. Ciênc. Admin, v. 19, n. 1, p. 16, 2013.

LIMONGI, Ana Cristina; ASSIS, Maria Paulina De. Projetos de Qualidade de Vida no Trabalho: Caminhos percorridos e Desafios. RAE Light, v. 35, p. 26-33, 1995.

LIMONGI-FRANÇA, Ana Cristina; KANIKADAN, Andréa Yumi Sugishita. A Construção de um Instrumento de Coleta de Dados a Partir do Modelo de Indicadores Biopsicossocial e Organizacional - BPS-96 e do Modelo de Competências do BemEstar - BEO, Sobre Gestão de Qualidade de Vida no Trabalho. Read, v. 12, n. 87, p. 24, 2006. 
LÍRIO, Angélica Barbieri; SEVERO, Eliana Andréa; GUIMARÃES, Júlio Cesar Ferro De. A Influência Da Qualidade De Vida No Trabalho Sobre O Comprometimento Organizacional. Gestao \& Planejamento, v. 19, p. 34-54, jan. 2018.

LOUVEIRA, Juliane; BRUSTOLIN, Regiane; DERROSSO, Giuliano. Qualidade de Vida no Trabalho no setor hoteleiro da cidade de Foz do Iguaçu. Navus - Revista de Gestão e Tecnologia, p. 58-71, 1 jan. 2018.

LUZ, Aldenora Souza Castro de; SOUZA, Luciana Silva de; SILVA, Rosangela Reis Lemes Da. Análise de QVT de trabalhadores do comércio na Amazônia caribenha. Revista de Administração de Roraima - RARR, v. 1, n. 1, p. 4, 28 set. 2011.

MAIA, Kadma Lanúbia da Silva; ARAÚJO, Richard Medeiros de; ALLOUFA, Jomaria Mata de Lima. Qualidade de vida no trabalho sob a ótica de servidores públicos: um estudo de caso em uma empresa pública federal. Revista Ciências Administrativas, v. 18, n. 2, 10 dez. 2014.

MARANHÃO, Marise Leal; SÁ, Maria Auxiliadora Diniz de. Cultura organizacional e práticas de qualidade de vida no trabalho: um estudo de múltiplos casos em palcos organizacionais de restaurantes do Recife - PE. Revista de Carreiras e Pessoas, v. 9, p. 266-286, 2 maio 2019.

MARQUES, Antônio Luiz; BORGES, Renata Simões Guimarães E; ADORNO, Ronara Dias. A LDB/96 e a qualidade de vida no trabalho:com a palavra os docentes da rede pública de belo horizonte. Revista de Ciências da Administração, v. 0, n. 0, p. 70-92, 27 jun. 2008.

MATIAS, Érika Pena Bedin; MOURA, Milena Cristina Correia de. Qualidade de vida no trabalho: um estudo de caso sobre Instituições Públicas Federais de Ensino Superior. Exacta - Ep. São Paulo, v. 17, n. 1, p. 10, 2016.

MATTOS, Carlos André Corrêa de et al. Qualidade de vida no trabalho: uma investigação multivariada entre docentes. Revista Eletrônica do Mestrado Profissional em Administração, v. 10, n. 1, p. 77-91, 2017.

MEDEIROS, Jassio Pereira; OLIVEIRA, José Arimatés. Uma Viagem à Produção Científica em Qualidade de Vida no Trabalho (QVT) nos anos 2001 a 2005: Estudo nos anais do ENANPAD. RECADM, v. 8, n. 1, p. 13, 2009.

MESQUITA, Rafael Fernande de et al. As dimensões da qualidade de vida no trabalho em empresas privadas. Exacta - Ep. São Paulo, Exacta. v. 16, p. 43-54, 2018.

MILHOME, Jaqueline Cavalcante; ROWE, Diva Ester Okazaki. Qualidade de Vida no Trabalho: Análise da Produção Científica entre 2006 e 2015. Gestão \& Planejamento, v. 17, n. 3, p. 499-519, 28 nov. 2016.

MILHOME, Jaqueline Cavalcante; ROWE, Diva Ester Okazaki; SANTOS, Marcos Gilberto Dos. Existem Relações Entre Qualidade de Vida no Trabalho, Comprometimento Organizacional e Entrincheiramento Organizacional? Contextus Revista Contemporânea de Economia e Gestão, v. 16, n. 3, p. 232-252, 12 dez. 2018.

MONACO, Felipe de Faria; GUIMARÃES, Valeska Nahas. Gestão da qualidade total e qualidade de vida no trabalho: o caso da Gerência de Administração dos Correios.

Revista de Administração Contemporânea, v. 4, n. 3, p. 67-88, dez. 2000. 
NASCIMENTO, Amilton da Costa. Análise Sobre a Qualidade de Vida no Trabalho dos Servidores o Instituto Federal de Roraima Campus Boa Vista Centro. Revista de Administração de Roraima - RARR, v. 6, n. 2, p. 322, 23 dez. 2016.

NASCIMENTO, Leandra Fernandes Do; PESSOA, Raimundo Wellington Araújo. Qualidade de Vida no Trabalho: Uma Questão de Responsabilidade Social. REAd, v. 13, n. 57, p. 587-611, 2007.

NESPECA, Milena; CAVALLINI, Denise Ciryllo. Qualidade de vida no trabalho de funcionários públicos: papel da nutrição e da qualidade de vida. Acta Scientiarum. Health Science, v. 33, n. 2, p. 187-195, 30 set. 2011.

OLIVARES, A.; BONITO, J.; SILVA, R. Qualidade de Vida no Trabalho dos Médicos da Atenção Básica no Estado de Roraima (Brasil). Psicologia, Saúde \& Doenças, v. 16, n. 2, set. 2015.

OLIVEIRA, Jonathan Silva de et al. Qualidade de Vida no Trabalho: Um Estudo Sobre a Avaliação Por Agentes de Segurança Penitenciária. RAunp, v. 5, p. 16, 2013.

OLIVEIRA, José Arimatés De; MEDEIROS, Jássio Pereira De. Modelos de Qualidade de Vida no Trabalho (|QVT): elementos para uma síntese. INTERFACE, v. 5, n. 1, p. 17,2008 .

OLIVEIRA, Lúcia Barbosa De et al. Efeitos da Tecnologia Móvel sobre a Qualidade de Vida no Trabalho. Revista Gestão \& Tecnologia, v. 15, n. 2, p. 25, 2015.

OLIVEIRA, Pablo Pedrosa Teixeira de; MINETTI, Luciano José; OLIVEIRA, Luciana Nunes de. Qualidade De Vida No Trabalho: Um Enfoque No Profissional De Secretariado Executivo De Uma Instituição Federal De Ensino Superior. Revista de Gestão e Secretariado, v. 3, p. 87-105, jul. 2012.

OLIVEIRA, Patrícia Morilha de; LIMONGI-FRANÇA, Ana Cristina. Avaliação da gestão de programas de qualidade de vida no trabalho. RAE eletrônica, v. 4, jun. 2005.

OLIVEIRA FILHO, Sandro et al. Qualidade De Vida No Trabalho: Um Estudo De Caso Com Os Docentes Do Departamento De Ciências Administrativas Da Ufrn. QUALITY OF LIFE AT WORK: A CASE STUDY WITH TEACHERS ON DEPARTMENT OF ADMINISTRATIVE SCIENCE FROM UFRN., v. 11, n. 3, p. 100118 , set. 2013.

OLIVEIRA, R. R et al. Qualidade de Vida no Trabalho - QVT dos Professores de Ensino Técnico Federal: Os Fatores Biopsicossociais e Organizacionais de Satisfação. Revista de Administração da Unimep, v. 11, n. 2, p. 143-173, 30 ago. 2013.

OLIVEIRA, Rodrgo Ribeiro et al. Qualidade de Vida no Trabalho (QVT): Um Estudo Com Professores dos Institutos Federais. HOLOS, v. 6, p. 432, 11 dez. 2015.

OLIVEIRA, Tiago Luz; SILVA, Luis Cláudio Jesus. Motivação dos servidores públicos: um caso na saúde pública na Amazônia. Revista de Administração de Roraima - RARR, v. 1, n. 2, p. 178, 15 jul. 2015.

PAIVA, Kely César Martins De; AVELAR, Vanessa Luciana Lima Melo De. Qualidade de vida no trabalho em uma central de regulação médica de um serviço de Atendimento Móvel de Urgência (SAMU). Organizações \& Sociedade, v. 18, n. 57, p. 303-321, jun. 2011. 
PAIVA, Luis Eduardo Brandão et al. Qualidade de Vida no Trabalho de Eletricitários do Estado do Ceará. REUNA, v. 22, n. 3, p. 19-38, 6 nov. 2017.

PANUCCI-FILHO, Laurindo; HEIN, Nelson; KROENKE, Adriana. Qualidade de Vida no Trabalho: um estudo do comprometimento organizacional na percepção de profissionais de contabilidade. Revista Foco, v. 10, n. 1, p. 178, 25 jan. 2017.

PEREIRA, Caroline Aquino; SALLES, Glauce Cristina Silva; PASSOS, Joanir Pereira. As Condições de Trabalho e Sua Relação Com a Saúde Dos Trabalhadores Condutores de Transporte. Revista de Pesquisa: Cuidado é Fundamental Online, n. Ediçao Supl, p. 904-907, 2010.

PESSOA, R.W.A.; NASCIMENTO, L.F. O Lazer como Ferramenta da Qualidade de Vida no Trabalho. Revista Organizações em Contexto, v. 4, n. 7, p. 18-34, 30 jun. 2008.

PICOLLI, Icaro Roberto Azevedo; CASAGRANDE, Jacir Leonir. Qualidade de Vida no Trabalho: uma análise bibliométrica em periódicos brasileiros entre 2005 à 2015 . Revista Foco, v. 10, n. 3, p. 172, 4 dez. 2017.

PINTO, Marli Dias Souza; KEMMER, Adélio Alvicio; FILIPPIM, Eliane Salete. Qualidade de Vida no Trabalho na Perspectiva dos Empregado de Uma Instituição Financeira. Revista Pensamento Contemporâneo em Administração, v. 5, n. 3, p. 83, 14 dez. 2011.

PIZZINATO, Adolfo; CARLOTTO, Mary Sandra; CÉ, João Pedro. Significados do trabalho e qualidade de vida percebida em trabalhadores do judiciário. Gerais: Revista Interinstitucional de Psicologia, v. 7, p. 11, 2014.

PIZZIO, Alex; KLEIN, Karla. Qualidade de vida no trabalho e adoecimento no cotidiano de docentes do Ensino Superior. Educação \& Sociedade, v. 36, n. 131, p. 493-513, jun. 2015.

POZO, Hamilton; TACHIZAWA, Elio Takeshy. Qualidade de Vida no Trabalho Nas Micro e Pequenas Empresas Como Vantagem Competitiva. REUNA, v. 21, n. 4, p. 81102, 31 dez. 2016.

QUEIROZ, Francisca Lígia Viana de et al. Qualidade de Vida no Trabalho (QVT): Estudo Comparativo em Três Campi de Uma Instituição Federal de Ensino no Rio Grande do Norte/RN. Revista de Administração da UNIMEP, v. 17, p. 1-33, jan. 2019.

RECHZIEGEL, Waldir; VANELLE, Rosângela Maria. Qualidade de Vida noTrabalho e a Gestão da Qualidade Total. Revista de Negócios, v. 4, p. 33-35, 1999.

REGIS FILHO, Gilsée Ivan; LOPES, Mônica Cristina. Qualidade de vida no trabalho: a empresa holística e a ecologia empresarial. Revista de Administração, p. 5, 2001.

REIS NETO, Mário Teixeira et al. Interações e Independências: Responsabilidade Social Empresarial, a Qualidade de Vida no Trabalho e a Qualidade de Vida em uma Empresa do Setor de Construção. Revista ADM.MADE, v. 19, p. 84-106, 2015.

ROCHA, Sandra de Souza Lima; FELLI, Vanda Elisa Andres. Qualidade de vida no trabalho docente em enfermagem. Revista Latino-Americana de Enfermagem, v. 12, n. 1, p. 28-35, fev. 2004.

ROSALINO, Caroline Bolzan; BARDAGI, Marucia Patta. Percepções de Funcionários de Uma Empresa de Transporte Urbano Sobre Qualidade de Vida no Trabalho. Barbarói, v. 0, n. 0, p. 120-137, 2008. 
SÁ, Maria Auxiliadora Diniz de. Qualidade de Vida no Trabalho Universitário: uma questão de prazer! INTERFACE, v. 12, p. 5-22, 2015.

SANTOS, Patrícia Silveira dos; BORGES, Gustavo Da Rosa. A influência da satisfação e qualidade de vida no trabalho entre alunos do curso de agronegócio. Revista de Carreiras e Pessoas (ReCaPe). ISSN 2237-1427, v. 8, n. 3, 3 set. 2018.

SANTOS, Vera Lúcia Dos et al. Estudo da qualidade de vida no trabalho de professores do ensino superior. REVISTA INTERSABERES, v. 14, n. 31, p. 187-197, 27 abr. 2019.

SCHIRRMEISTER, Renata; LIMONGI-FRANÇA, Ana Cristina. A Qualidade de Vida no Trabalho: Relações com o Comprometimento Organizacional nas Equipes

Multicontratuais. Revista Psicologia: Organizações e Trabalho, v. 1, n. 12, p. 283-298, 2012.

SCHMIDT, Denise Rodrigues Costa et al. Qualidade de vida no trabalho e burnout em trabalhadores de enfermagem de Unidade de Terapia Intensiva. Revista Brasileira de Enfermagem, v. 66, p. 13-17, fev. 2013.

SCHMIDT, Denise Rodrigues Costa; DANTAS, Rosana Aparecida Spadoti;

MARZIALE, Maria Helena Palucci. Quality of life at work: Brazilian nursing literature review. Acta Paulista de Enfermagem, v. 21, n. 2, p. 330-337, 2008.

SILVA, Armistrong Martins da. Qualidade de Vida no Trabalho (QVT): uma avaliação em uma concessionária de energia elétrica na cidade de Mossoró/RN, Brasil. Exacta Ep. São Paulo, v. 15, p. 527-540, 2017.

SILVA, Cleide Aparecida da; FERREIRA, Maria Cristina. Dimensões e indicadores da qualidade de vida e do bem-estar no trabalho. Psicologia: Teoria e Pesquisa, v. 29, n. 3, p. 331-339, set. 2013.

SILVA, Jaqueline Miranda Baarros et al. Nível de satisfação: fator gerador de qualidade de vida no trabalho / Level of satisfaction: factor generator of quality of life at work. Revista de Pesquisa: Cuidado é Fundamental Online, v. 10, p. 343-350, 2 abr. 2018.

SILVA JUNIOR, Annor da et al. Qualidade de Vida no Trabalho e Níveis Hierárquicos. Pretexto, v. 13, p. 154-178, 2012.

SILVA, Narbal; TOLFO, Suzana da Rosa. Trabalho Significativo e Felicidade Humana: Explorando Aproximações. Revista Psicologia: Organizações e Trabalho, v. 12, p. 341-354, 2012.

SILVA, Thalita Kestering; VOLPATO, Débora; RONSANI, Cleusa. Análise da Qualidade de Vida no Trabalho em Uma Empresa do Setor de Tecnologia da Informação Localizada na Cidade de Criciúmas - SC. Revista de Carreiras e Pessoas (ReCaPe). ISSN 2237-1427, v. 8, n. 2, 2 maio 2018.

SOUZA, Janice Janissek de; BASTOS, Antônio Virgílio Bittencourt. Programas de Qualidade de Vida no Trabalho em Contextos Diferenciados de Inovação: Uma Análise Multivariada. REAd. Revista Eletrônica de Administração (Porto Alegre), n. 63, p. 14, 2009.

SOUZA, Josiane Aparecida Cardoso de; MAZINI FILHO, Mauro Lúcio. Análise ergonômica dos movimentos e posturas dos operadores de checkout em um supermercado localizado na cidade de Cataguases, Minas Gerais. Gestão \& Produção, v. 24, n. 1, p. 123-135, 23 fev. 2017. 
SOUZA, Lícia Barcelos de; FIGUEIREDO, Marco Antônio de Castro. Qualificação profissional e representações sobre trabalho e qualidade de vida. Paidéia (Ribeirão Preto), v. 14, n. 28, p. 221-232, ago. 2004.

SOUZA, Washington José de; MEDEIROS, Jássio Pereira De. Diagnóstico da Qualidade de Vida no Trabalho (QVT) de Frentistas de Postos de Combustíveis e Suas Interfaces Com a Qualidade dos Serviços Prestados. Revista de Gestão USP, v. 14, n. 3 , p. 71-89, 2007.

SOUZA, Amanda Oliveria Dea de et al. Qualidade de vida no trabalho em uma cooperativa de reciclados. Revista de Carreiras e Pessoas (ReCaPe) | ISSN-e: 22371427, v. 9, n. 3, 2 set. 2019.

SOUZA, Sulma Vanessa et al. Qualidade de vida no trabalho em unidades produtoras de leite: uma análise a partir do modelo de Walton. Agrarian, v. 12, n. 44, p. 223-236, 12 out. 2019.

STEFANO, Silvio Roberto et al. Satisfação da qualidade de vida no trabalho com relação aos fatores biopsicossociais e organizacionais: um estudo comparativo entre docentes das universidades pública e privada. Revista Gerenciais, v. 5, p. 35-44, 2006.

TIECHER, Bruna; DIEHL, Liciane. Qualidade de Vida no Trabalho na Percepção de Bancários. Pensamento \& Realidade, v. 32, p. 41-60, 2017.

TIMOSSI, Luciana et al. Adaptação do modelo de Walton para avaliação da Qualidade de Vida no Trabalho. Revista da Educação Física/UEM, v. 20, n. 3, p. 395-405, 5 out. 2009.

TODESCHINI, Remigio; FERREIRA, Mário Cesar. Olhar de dirigentes sindicais sobre qualidade de vida no trabalho e mal-estar no trabalho. Estudos de Psicologia (Natal), v. 18, p. 241-247, jun. 2013.

TOLFO, Suzana da Rosa; PICCININI, Valmíria Carolina. As melhores empresas para trabalhar no Brasil e a qualidade de vida no trabalho: disjunções entre a teoria e a prática. Revista de Administração Contemporânea, v. 5, p. 165-193, abr. 2001.

VASCONCELOS, Patricio Henrique de et al. Quality of The Working Life Of Teachers: A Case Study At a Higher Education Institution. Review of Administration and Innovation - RAI, v. 9, n. 2, p. 79-97, 4 jul. 2012.

VENELLI-COSTA, Luciano et al. Fatores de Qualidade de Vida no Trabalho e Sucesso na Carreira: Um Estudo Com Médicos da Cidade de Belo Horizonte. RAHIS, v. 14, n. 3 , 9 abr. 2018.

VENSON, Aline Botelho Schneider et al. O recurso mais importante para as organizações são mesmo as pessoas? Uma análise da produção científica sobre qualidade de vida no trabalho (QVT). Revista de Administração da UFSM, v. 6, n. 1, p. 139-156, 12 abr. 2013.

VIEIRA, Adriane. A Qualidade de Vida no Traballho na Gestão da Qualidade Total. Revista de Negócios, v. 2, p. 17-35, 1996.

VIEIRA, Renato Paulo Lopes et al. Qualidade de Vida e Bem-Estar no Trabalho: Autopercepção Dos Servidores de Uma Universidade Federal. HOLOS, v. 6, p. 171184, 3 dez. 2018. 
VILAS BOAS, Ana Alice; MORIN, Estelle M. Indicadores de Qualidade de Vida no Trabalho Para Professores de Instituições Públicas de Ensino Superior: Uma Comparação Entre Brasil Canadá. Contextus - Revista Contemporânea de Economia e Gestão, v. 14, p. 170-198, 26 out. 2016.

VILAS BOAS, Ana Alice; MORIN, Estelle M. Qualidade de Vida no Trabalho: Um Modelo Sistêmico de Análise. Revista Administração em Diálogo - RAD, v. 19, n. 2, p. 62, 1 maio 2017.

VITAL, Mirian Serrão; PAIVA, Kely César Martins de. Qualidade de vida no trabalho e vínculos organizacionais: Proposição de um modelo integrativo e perspectivas de pesquisas. Gestão \& Planejamento, v. 20, p. 635-659, 20 set. 2019.

WALTON, Richard E. Quality Of Working Life: What Is It? Sloan Management Review, v. 15, p. 11-21, 1973.

WERTHER, William B.; DAVIS, Keith. Administracao de Pessoal e Recursos Humanos.

WESTLEY, William A. Problems and Solutions in the Quality of Working Life. Human Relations, v. 32, n. 2, p. 113-123, 1 fev. 1979.

WILLEMANN, Amanda Cristina; FERREIRA, Ana Cristina. Qualidade de Vida no Trabalho em Uma Empresa de Transporte de Passageiros e Fretamento do Alto Paranaíba - MG. Qualitas Revista Eletrônica, v. 18, n. 3, p. 88-112, 28 mar. 2018.

ZANARDI, Eduardo et al. Correlações entre qualidade de vida no trabalho e comprometimento organizacional: estudo em uma unidade de varejo de vestuário na cidade de Joinville/SC. Revista Produção Online, v. 15, n. 2, p. 573-600, 15 jun. 2015.

ZWIELEWSKI, Graziele; TOLFO, Suzana da Rosa. Qualidade de Vida no Trabalho de Profissionais Expatriados Para Índia e China. REAd. Revista Eletrônica de Administração (Porto Alegre), v. 22, p. 510-542, ago. 2016. 